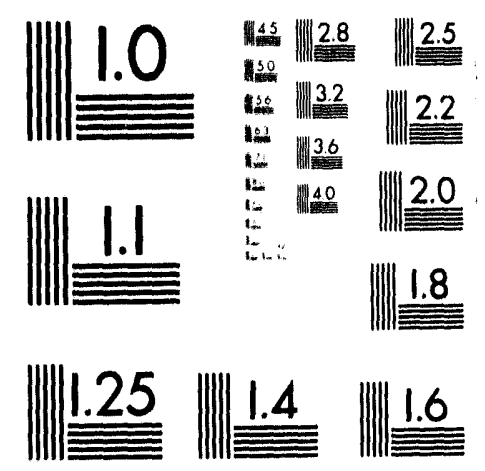




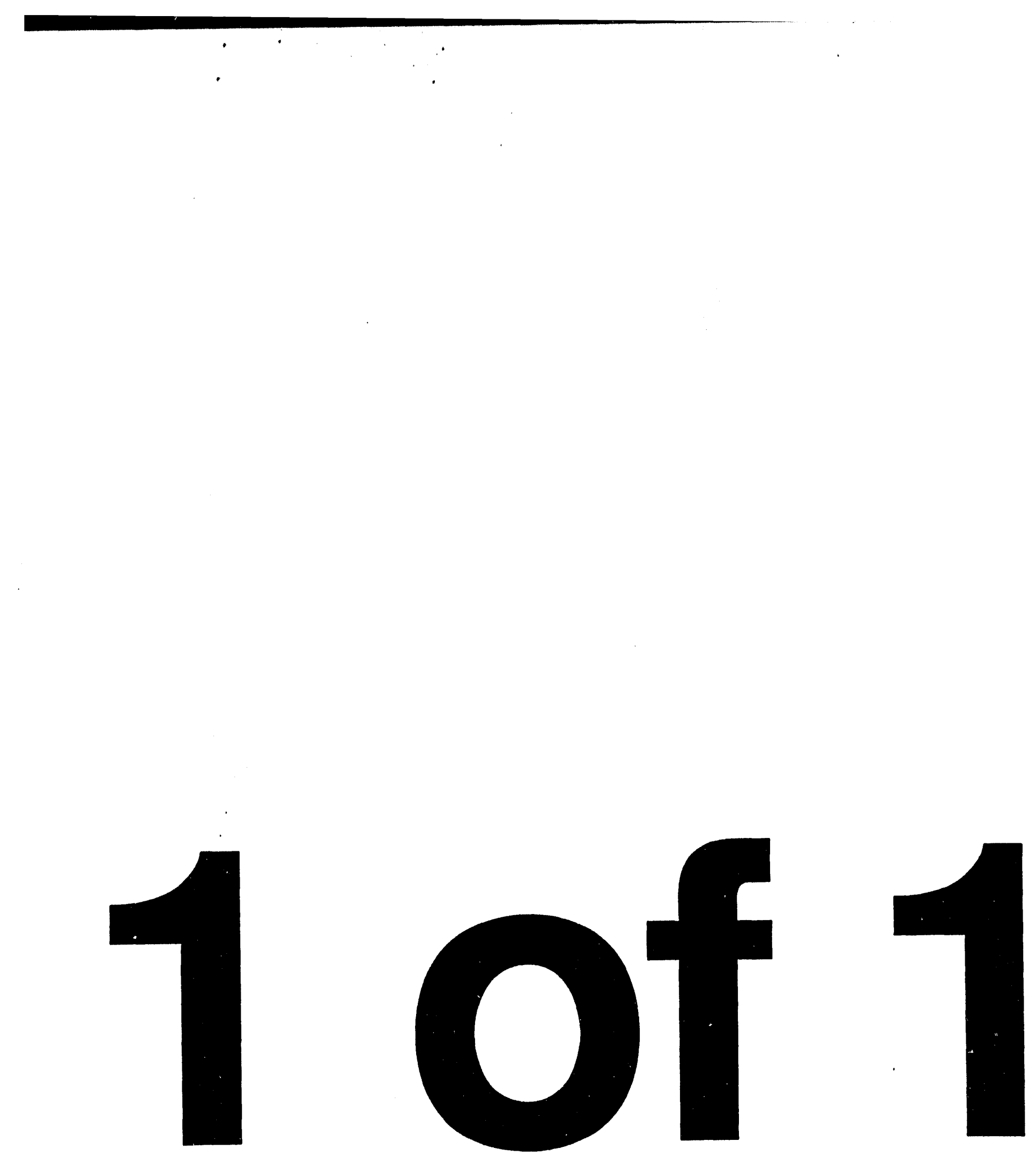




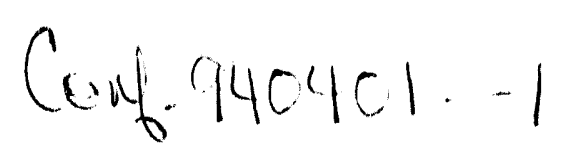

LA-UR- $93-8690$

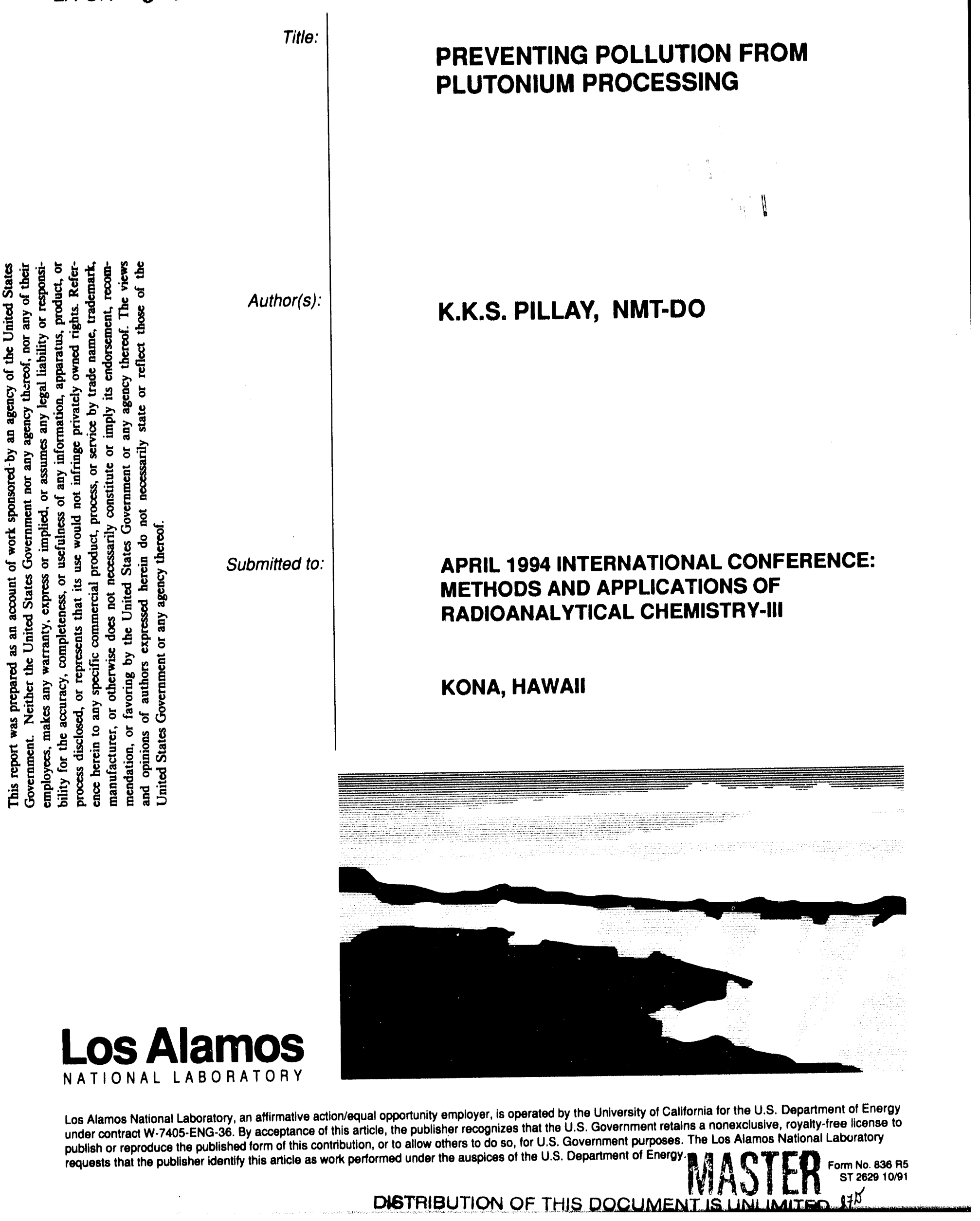


October 8, 1993

\title{
PREVENTING POLLUTION FROM PLUTONIUM PROCESSING
}

\author{
K. K. S. Pillay, NMT Division, Los Alamos National Laboratory, \\ Los Alamos, NM 87545 (USA)
}

\begin{abstract}
The plutonium processing facility at Los Alamos has adopted the strategic goal of becoming a facility that processes plutonium in a way that produces only environmentally benign waste streams. Pollution prevention through source reduction and environmentally sound recycling are being pursued. General approaches to waste reductions are administrative controls, modification of process technologies, and additional waste polishing. Recycling of waste materials, such as spent acids and salts, are technical possibilities and are being pursued to accomplish additional waste reduction. Liquid waste stream polishing to remove final traces of plutonium and hazardous chemical constituents is accomplished through (a) process modifications, (b) use of alternative chemicais and sorbents for residue removal, (c) acid recycling, and (d) judicious use of a variety of waste polishing technologies. Technologies that show promise in waste minimization and pollution prevention are identified. Working toward this goal of pollution prevention is a worthwhile endeavor, not only for Los Alamos, but for the Nuclear Complex of the future.
\end{abstract}

\section{INTRODUCTION}

During the past 40 years, a number of environmental laws and regulations have been promulgated by the US Congress and this process has accelerated to the point they have become a critical factor in the quality of life in the US. Ever since the passage of the National Environmental Policy Act (NEPA) in 1969, there have been increasing legal requirements to minimize the environmental impact of a range of human activities. Figure-1 is a representation of the cumulation of environmental regulations since 1953 . For nearly two decades after the passage of NEPA, the US defense programs sought refuge under the Atomic Energy Act and claimed sovereign immunity from NEPA compliance. During the past few years, however, a new culture has evolved in the defense sector that has changed past attitudes toward environmental impact of defense-related activities and attempted changes to make changes to the legacy of nuclear wastes in the US. This has culminated in the passage of the 1992 Federal Facility Compliance Act, which mandates Federal facilities to comply with all applicable environmental regulations and that a deliberate effort be made to comply with these 
regulations before October 1995. This latter legislation has been a great motivator to all Federal facilities, including the plutonium processing facility at Los Alamos, to modify past practices and to become conscious of environmental impacts of all their activities.

Figure-1. Cumulation of Environmental Regulations in the US.

In recent years, the U.S. Department of Energy (DOE) has elevated environmental restoration and waste management to major mission areas, and it has established reduction of wastes from DOE facilities as a major objective. DOE facilities must now comply with all environmental regulations, including special regulations required of Federal facilities. In recognition of this shift in philosophy, the plutonium processing facility at Los Alamos has adopted the goal of becoming a facility that processes plutonium in a way that produces only environmentally benign waste streams.

As part of Los Alamos National Laboratory's mission to maintain expertise and skills in nuclear weapons technologies, the plutonium processing facility at Los Alamos is dedicated to maintaining excellence in chemistry and metallurgy or plutonium. A variety of aqueous and pyrochemical processes are used to chemically isolate plutonium from a variety of complex matrices and to produce high-purity metal. These processes create a variety of waste streams that need careful management. During the past five decades, technologies for processing plutonium have undergone numerous changes. There have been parallel changes in waste streams from such operations. Although the legacy of radioactive wastes from past defense production has created the need for major investments in waste management and environmental restoration, the future has to be one of compliance with all environmental regulations and responsible management of processes and waste streams.

A variety of approaches are being examined to achieve the above mentioned goal. We have identified a combination of process flow sheet changes that will (1) avoid the use of hazardous chemicals for processing, recovering, and recycling chemicals and (2) polish all waste streams coming from the facility to eliminate both hazardous and radioactive constituents. A focused research and development program is directed at achieving the goal of a facility with zero environmental impact. Perceptions of costs have been limiting factors in the past. The benefits of complying with environmental emission standards and addressing the public's concern over the legacy of nuclear wastes are not quite quantifiable. Becoming a facility with zero radionuclide and mixed waste discharge is an extremely challenging goal and one that requires the technical contributions of a 
multidisciplinary team of experts. While all the technologies necessary to achieve this goal are not yet available, an extensive knowledge base does exist that can be applied to solving remaining problems.

\section{WASTE STREAMS FROM PLUTONIUM RESIDUES PROCESSING}

Plutonium- containing residues are generated at all phases of the production and recycling of plutonium components and during chemical processing of residues to recover plutonium. Throughout the DOE complex, over 100 different types of plutonium residues are generated 1 . These residues are variously categorized as primary and secondary 2 . Scrap materials generated from foundry operations involving casting, alloying, forging, and machining of metal are identified as primary residue. Also, included in this category is graphite from molds, fused salts from extractive metallurgy, and plutonium oxide from burnt casting. Secondary residues result from processing of primary residue items. These include incinerator ash, heels from various primary treatment, crucibles, filters, and a variety of combustibles.

Two major processes used for plutonium recovery at Los Alamos are aqueous processing and pyrochemical processing. Figure-2 is a simple schematic of the processes used in plutonium recovery from residues 1 . For aqueous processing, depending on the nature of materials involved, a variety of dissolution procedures are used to get the matrices in solution. Primary dissolution media are nitric or hydrochloric acids. From aqueous solutions thus formed, plutonium is selectively removed by solvent extraction or ion exchange. A great variety of extractants and absorbers are useful to achieve this separation. The extracted plutonium is generally reprecipitated as an insoluble form (hydroxide, oxalate, peroxide, etc.) and calcined to a stable oxide form for long-term storage. The oxide or other intermediate chemical forms, such as fluoride, may be used as starting material for producing plutonium metal through a bomb-reduction process. Further purification of plutonium is achieved through molten salt extraction and electrorefining. Both these processes are pyrochemical, and there are numerous variations to these processes as well.

Figure-2. Plutonium Residue Processing

The waste streams resulting from these operations are numerous and contain varying amounts of plutonium. In general, gaseous waste streams are likely to contain toxic gases and fine particles of plutonium. Toxic gases are removed by scrubbing with appropriate reagents, and plutonium particulates are removed by high efficiency particulate air filters. For a long time, the plutonium 
facility at Los Alamos has been successful in eliminating all toxic gases and radioactive particulates from air emissions and has been in full compliance with all regulatory requirements and clean air standards.

Other waste streams from these processes include insoluble scrap residue, spent ion exchangers, spent liquid extractant, filtrates from precipitation, spent crucibles from bomb reduction, anodic residues from electrorefining, and spent salts from molten salt extraction and electrorefining. In addition, other contaminated materials (such as dry box gloves, disposable gloves, glass windows of dry boxes, rags, contaminated glass vessels, other containers, Raschig rings, and contaminated paper and clothing) require decontamination, interim storage, and eventual disposal. Since plutonium is considered a toxic material, all these waste forms have to be properly managed and isolated from human environment. Since plutonium was considered a very valuable material, a variety of processes were developed at Los Alamos to extract plutonium from all the primary residues and most of the secondary residues.

Some of the special problems associated with plutonium processing are criticality safety, radiation exposure, and nuclear material safeguards issues. These problems, which are unique to plutonium processing, also contribute to increased secondary waste generation.

\section{WASTE MINIMIZATION AND POLLUTION PREVENTION}

Waste minimization, a step toward pollution prevention, is any action that avoids or reduces the generation of wastes. Ideal pollution prevention approaches are (1) source reduction and (2) environmentally sound recycling. With significant reduction in nuclear weapons requirements, a major waste minimization mechanism is through source reduction. Recycling of waste materials is a technical possibility and can accomplish additional waste reduction. Additionally, potential waste materials that cannot be eliminated or minimized may be treated to reduce their volume, toxicity, or mobility prior to storage or disposal.

The nuclear facilities of the future will take DOE's ambitious plans for waste minimization a step further by using new technologies to ensure that their operations have little or no impact on the environment. New technology development for waste minimization and waste management are key 
components of both near- and long-term goals of a strategic plan developed for the plutonium processing facility at Los Alamos.

\section{APPROACHES TO WASTE MINIMIZATION}

General approaches to waste reductions are administrative controls, modification of process technologies, and additional waste treatment at the facility. Liquid waste stream polishing to remove final traces of plutonium and hazardous chemical constituents is possible through (a) process modifications, (b) use of alternative chemicals and sorbents for removal, (c) acid recycling, and (d) judicious use of a variety of waste polishing technologies. Solid waste streams can be significantly reduced through proper sorting at the source and further screening to isolate contaminated solids.

A variety of technologies that show promise for waste reduction are being examined for incorporation into plutonium processing flow-sheets. In addition, technologies that have been routinely used in other industries, such as the semiconductor industry (plasma decontamination), ceramic industry (magnetic separation), and copper industry (magnetite beads coated with ion exchangers), can be adapted and integrated with new technologies that show promise. A major goal of plutonium processing at Los Alamos is to systematically target ways to reduce and eliminate waste. Because of space limitations, only a few examples of liquid and solid waste stream polishing are presented in the following paragraphs. Air-borne emissions are not discussed because the plutonium facility at Los Alamos is in compliance will all standards for air-borne emissions, and these standards can be readily maintained.

\section{A. Liquid Waste Stream Polishing}

The liquid waste effluents from a plutonium processing facility contain large quantities of nitric and hydrochloric acids and traces of actinides. These streams can be polished through some combination of technologies listed above. A systematic approach to accomplishing liquid waste stream polishing can lead to (1) the recovery of almost all the acids for recycling, and (2) the generation of liquid waste with an alpha-activity that meets drinking water quality. Such clean water can be reused at the facility and excess water can be directly released to the environment without further processing.

Acid recycling has been in use for many decades. However, the recovery of acids from alphaactive waste streams is not very common. Nitric acid recycling from aqueous nitrate plutonium 
process lines have been demonstrated at Los Alamos ${ }^{3}$. However, routine recycling is still not a reality at this time. A commercially available system is being examined for potential use in a glovebox environment to recycle both nitric and hydrochloric acids from process lines. ${ }^{4}$

One of the major technical accomplishments at Los Alamos in recent years is the development of a fully integrated, modular plutonium processing facility, known as the ATLAS line (Advanced Testing Line for Actinide Separations). 5 The plutonium content of liquid streams from this process line has been reduced by nearly two orders of magnitude. Still, these streams do not qualify for direct release to the environment. The residual amounts of plutonium in the stream are tine colloidal particles that cannot be removed by conventional filtration techniques or ion exchange processes. Technologies, such as use of specially designed ligands and ion exchangers, high magnetic field separation of particulate, and freeze-drying, are considered promising when used in combination. Such technologies are extensively used in industry for material processing and other waste management activities. On-going laboratory-scale experiments will determine if these technologies can polish final traces of plutonium and other actinides from liquid effluents to produce effluents that can he released directly to the environment.

An alternative approach being examined is the use of freeze-drying to remove dissolved solutes and colloidal suspensions from liquid waste streams. This technology has shown considerable promise in initial tests by achieving a decontamination factor of 106 or more during a single stage operation. Freeze-drying technology is well developed and is routinely used in the food processing industry. A variation of this technology can be readily adapted to recover solvents, rather than solutes.

\section{B. Solid Waste Stream Polishing}

Solid waste stream polishing to remove radioactive residue is a fundamentally difficult task. Simple processes, such as washing solid residues and treating liquid streams generated, have achieved little overall reduction of waste streams. There are, however, technologies that can volatilize plutonium contamination from surfaces of materials, such as contaminated tools and equipment, gloves, and clothing. For example, it is well known that active fluorine species, either in molecular or atomic form, can remove surface plutonium, which can thereby be separated from the matrix.6,7 Moreover, it has been demonstrated that actinide contamination can be removed from conductive surfaces using electrolytic techniques. 8 Similarly, the paramagnetism of actinides could be used in a preliminary procedure to separate actinide-bearing solid residues, such as ashes, salts, soils, and residues, into rich and lean fractions.9 A waste form that is unique to plutonium recovery and metal production is salt 
residues. An elegant technique recently developed at Los Alamos is capable of removing almost all traces of plutonium from the salt matrix without any additional waste streams. 10 It would seem that a combination of these technologies might remove plutonium residues from a variety of solid waste forms generated at the plutonium processing facility.

A unique problem recognized at most nuclear materials processing facilities is the commingling of clean solid wastes (such as paper, cardboard, plastics, etc.) with contaminated materials of similar type. About $60 \%$ of the miscellaneous solid wastes removed from the plutonium facility at Los Alamos are innocuous solids. Separation of this bulk from contaminated waste can significantly reduce both the amount of contaminated waste leaving the facility and the cost of waste disposal. An approach being pursued is to install "White-Top" waste containers at various locations to collect uncontaminated solid wastes. Since these containers have the potential to contain contaminated discards, the wastes from the white-top containers will be screened for radioactive contamination using highly sensitive detector systems using an array of low-energy gamma detectors and neutron detectors placed above a waste stream conveyor system. Uncontaminated waste from this stream will be disposed of in surface landfills, similar to municipal waste dumps.

In nature, waste reduction and waste elimination are accomplished through destruction of organic materials to produce carbon dioxide and water and through oxidation of inorganics to generate stable forms. Incineration, the industrial equivalent to these natural processes, has not been fully accepted by the public in the U.S. However, this technology can be properly adapted and can demonstrate to the satisfaction of its critics that oxidative thermal treatment is a highly desirable technology for waste reduction and pollution prevention. We hope to integrate this approach with other technologies to reduce and eliminate wastes from plutonium processing at Los Alamos.

\section{SUMMARY}

Future nuclear materials processing facilities have a major responsibility to properly treat and dispose of nuclear wastes. A variety of actions are essential to the survival of nuclear facilities and the continued beneficial uses of nuclear technologies. Future facilities must be able to function without the release of radioactive and hazardous materials to the environment. Dilution and dispersion of wastes practiced in the past must stop altogether. Immobilization and isolation of wastes from the biosphere will have only a limited role in the long-term management of nuclear wastes. Sequential repository construction and geologic disposal as a solution to nuclear wastes 
problems is not practical. Stabilization and storage should be seriously considered as an option so that valuable resources are not discarded for political expediency. A national policy must be developed wherein an acceptable repository for future storage of radioactive materials would be a managed storage vault.

The legacy of nuclear wastes distributed across the nation in difficult-to-manage matrices requires an innovative policy for the future operation of nuclear facilities for national defense and energy production. Managed storage of concentrated nuclear materials can be the policy for the national defense sector. Lessons of the past fifty years dictate that a new attitude and responsible management of nuclear materials are essential to maintaining a national nuclear deterrent and the future option of nuclear energy. Presently a number of avenues are being explored to eliminate excess inventories of fissile materials removed from the weapons stockpile. It is essential that these technological approaches first consider the legacy of nuclear wastes and incorporate technologies that will ensure responsible management of all future technologies and the wastes they generate.

\section{REFERENCES}

1. Nuclear Materials: Plutonium Processing in the Nuclear Weapons Complex," GAO-RECD-92. 109FS, United States General Accounting Office, Washington, D.C. (August 20, 1992).

2. D. C. Christensen, D. F. Bowersox, B.J. McKerley, and R. L. Nance, "Wastes from Plutonium Conversion and Scrap Recovery Operations," LA-11069-MS, Los Alamos National Laboratory, Los Alamos, NM (March 1988).

3. S. B. Schreiber, W. A. Punjak, and S. L.Yarbro, "Aqueous Nitrate Flowsheet Optimization and Enhancement Using ATLAS Facility," LA-UR-93-2440, Los Alamos National Laboratory, To be published in the Proceedings of the AIChE 1993 Summer National Meeting held in Seattle, WA (August 1993).

4. Personal Communication from Evan O. Jones, Viatech Recovery System, Inc. Richland, WA (August 21, 1993). 
5. N. G. Pope, S. L.Yarbro, S. B. Schreiber, and R. S. Day, "An Introduction to the Advanced Testing Line for Actinide Separation," LA-12156, Los A amos National Laboratory, Los Alamos, New Mexico (March 1992).

6. K. C. Kim and G. M. Camphell, "Fourier Transform Infrared Spectrometry Using a VeryLong-Pathlength Cell: Dioxygen Difluoride Stability and Reactions with Plutonium Compounds," Applied Spectroscopy, 39(4), 625 (1985).

7. J. C. Martz, "Plasma Chemical Processing," LA-LP-9241, Los Alamos National Laboratory, Los Alamos, NM., pp 26-33, (1992).

8. G. M. Campbell, T. O. Nelson, J. L. Parker, R. H. Getty, T. R. Hegert, K. A. Lindahl, and L. G. Peppers," LA-UR-93-3404 Proceedings of the Actinide-93 International Conference held in Santa Fe, NM (Sept.1993).

9. L. R. Avens, L. A. Worl, K. J. deAguero, F. C. Prenger, W. F. Stewart, and D. D. Hill, “ Opp "unities for Magnetic Separation Applirations on Complex-21," LA-LP-9241, Los Alamos National Laboratory, Los Alamos, Nm., pp 69-73, (1992).

10. E. Garcia, W. J. Griego, D. B. Court, and L. Rodriguez, "Applicability of Molten Salt Oxidation to the Destruction of Actinide -Contaminated Wastes," in Emerging Technologies for Hazardous Waste Management, Vol. 1, 57, American Chemical Society, Washington, D.C. (1992). 


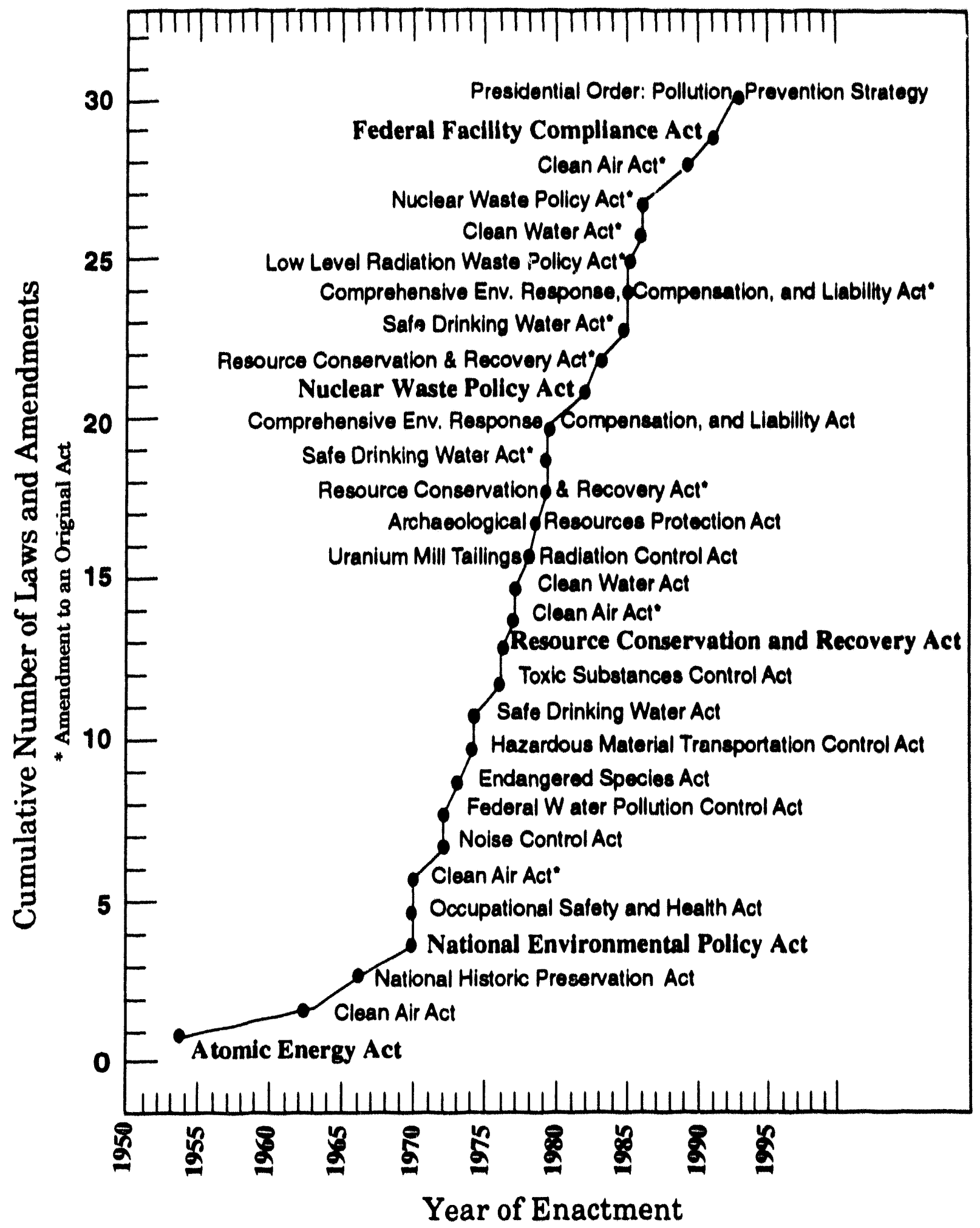

Fig. 1. Cumulation of Environmental Regulations in the US. 


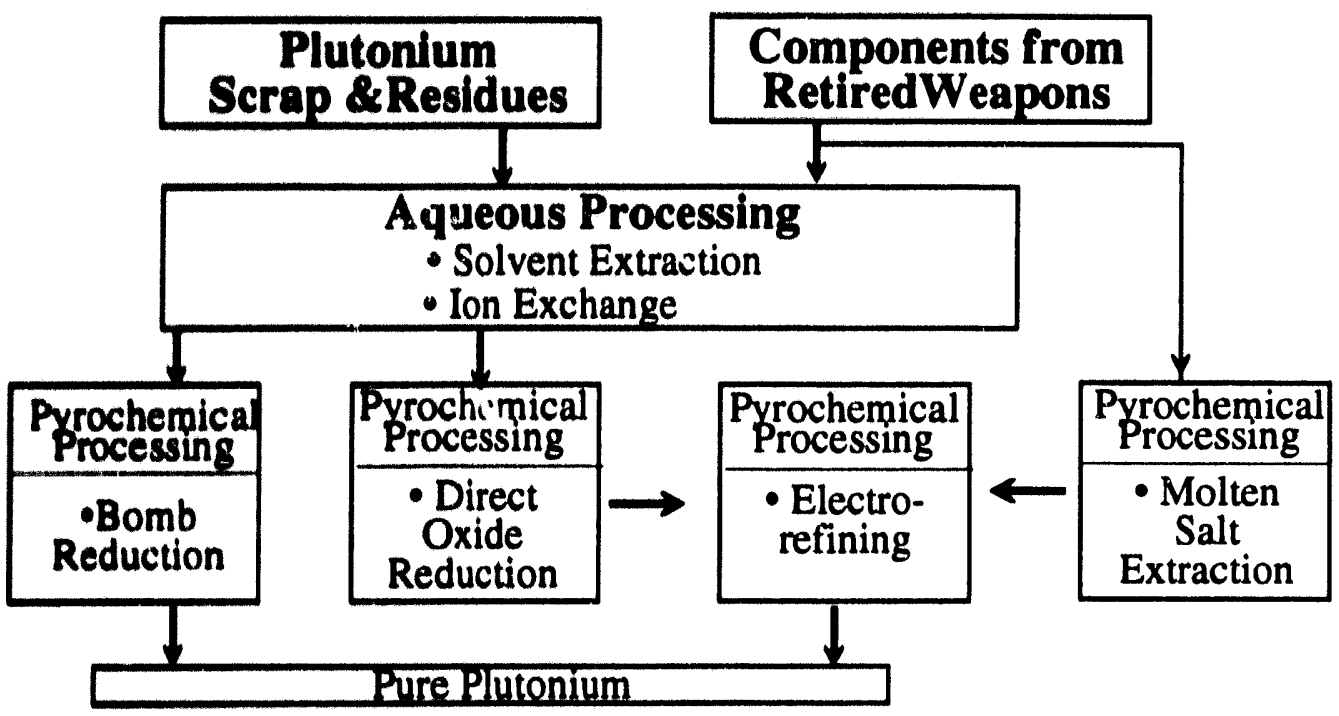

Fig. 2. Generic processing of plutonium residues 

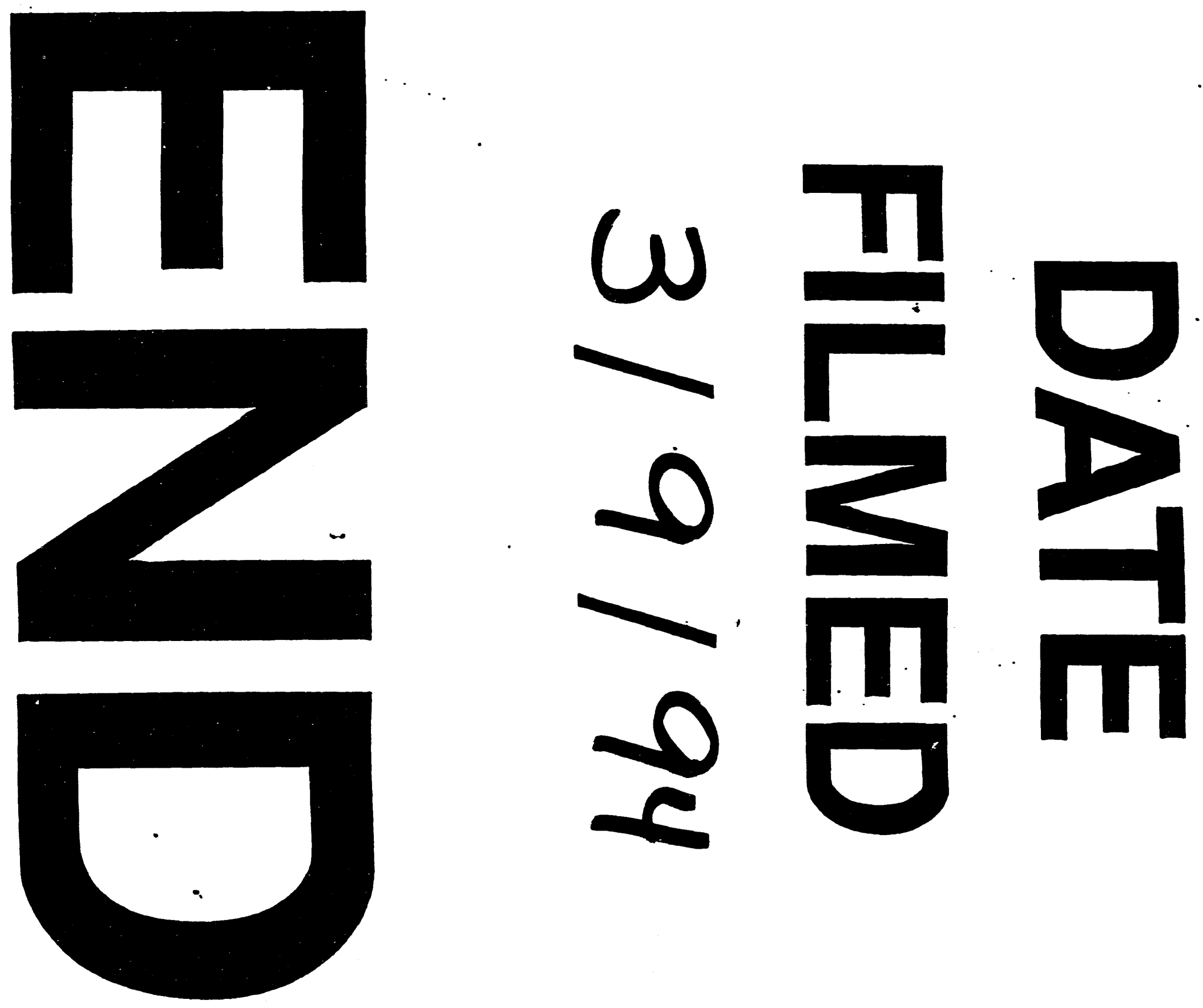


\section{-}

